\title{
THE STUDY OF INFLUENCE OF TECHNOLOGICAL FACTORS OF ENCAPSULATED OILS AND THEIR SHELL PRODUCTION USING SODIUM ALGINATE
}

\author{
Olga Neklesa \\ Department of Technology of Bread, Confectionery, Pasta and Food Concentrates \\ Kharkiv State University of Food Technology and Trade \\ 333 Klochkivska str., Kharkiv, Ukraine, 61051 \\ olgapyvovarova52@mail.ru \\ Evgeniya Korotayeva \\ Department of Food Technology \\ Kharkiv State University of Food Technology and Trade \\ 333 Klochkivska str., Kharkiv, Ukraine, 61051 \\ Korotayeva1990@gmail.com \\ Oleksander Nagorniy \\ Department of Food Technology \\ Kharkiv State University of Food Technology and Trade \\ 333 Klochkivska str., Kharkiv, Ukraine, 61051 \\ niv1112@ukr.net
}

\begin{abstract}
The use of sodium alginate and realization of its chemical potential in technology of encapsulated oils provide thermostable properties of shell that widens the assortment of new types of oil-fat products with given geometric form and improved consumption properties, prolonged storage terms.

The stable technological process of encapsulated oil production is provided by involvement of third substance - white sugar into recipe composition of sodium alginate water solution.

Scientific-technical substantiation of the composition of structurized edible shells of dosed encapsulated oils is provided by the parameters of such systems that determine technological cycle of production and of the work of special equipment for its industry receiving.

The technology of shells of encapsulated oils and rational concentrations of recipe components were elaborated. The introduction of density regulator - white sugar - in concentration 23,0 \% into the composition of capsule-creating solution that allowed determine organoleptic and structural-mechanical parameters $\mathrm{E}_{\mathrm{fr}}=(10,0 \ldots 21,5) \times 10^{3} \mathrm{~Pa}$ was substantiated. Determination of technological properties of the shell of encapsulated oils gives preconditions for the industrial production that allows widen the assortment of oil-fat raw material, encapsulated charging and widen the area of the use of industrial encapsulated product for culinary at institutions of restaurant economy.

Keywords: spherification, model, capsule head, device, complex creator, calcium ions, mechanism, hydromodule.
\end{abstract}

\section{Introduction}

Last years the expressed tendency to the growth of demand for the products of healthy food and use of semi-products of high readiness degree for making culinary with balanced composition is observed. To certain extent it concerns the oil and fat raw material [1-4].

Elaboration and realization of the technology of encapsulated oils has marketing attractiveness because of unique commodity form of oil-fat raw material $[5,6]$ on the market. At the same time encapsulated product has innovative attractiveness for the oil-fat complex and functionality in the aspect of technological use for culinary and food products. We know technologies of the oils and fats production in encapsulated form that are divided by the method of receiving that are inherent mainly to pharmaceutical branch [7]. There are, first of all, enriched oil-fat stuffs in gelatinous capsules [7]. It is well-known, that gelatins create non-thermostable gels that at the temperature that exceeds melting point transfer into solution of high-molecular compounds (HMC), so the use 
of such oil-fat capsules in composition of hot snacks, warm salads and culinary production that undergo thermal processing is impossible.

The scientific grounding of parameters of technological process and recipe composition of the shells of encapsulated oils is necessary to provide the industrial production of hydrophobic systems on the base of sodium alginate [8].

Encapsulated oils can be used as an independent product, semi-product of high readiness, décor element in business processes B2C, B2B and in technological processes of production of the segment of culinary, floury and confectionary meals. The methods of encapsulated oils production are directed, first of all, on its use for organization of nourishment of population.

The scientists' experience $[9,10]$ as to AlgNa use in encapsulation technologies has unexhausted resource, so its realization takes place in substantiation of encapsulated oils technology.

The direction of transformation of the oil-fat raw material into encapsulated form with thermostable shell on the base of ionotropic polysaccharides is prospective. This way allows widen the assortment of oil-fat raw material, provide its intactness in technological process of culinary production and elaborate the new commodity form that will favor the solution of numerous technological tasks in branch by its functional-technological properties.

\section{Materials and Methods}

$\mathrm{AlgNa}$ solutions was received by disintegration of its batch in drinking water, prepared at temperature $\mathrm{t}=18 \ldots 20^{\circ} \mathrm{C}$ during $\tau=(3 \ldots 4) \times 60^{2} \mathrm{~s}$ on magnetic mixer. The received AlgNa solution was placed in vacuum-exicator and degazation of the solution was carried out during $\tau=(30 \ldots 60) \times 60^{2} \mathrm{~s}$.

Encapsulated oils in industrial conditions were received on author capsulating device UGK-20 G by LTD "Capsulator" (Ukraine) with power $25 \mathrm{~kg}$ /hour, the graph presentation of its capsule head is given on the Fig. 1, and mechanism of receiving of encapsulated oils on the Fig. 2.

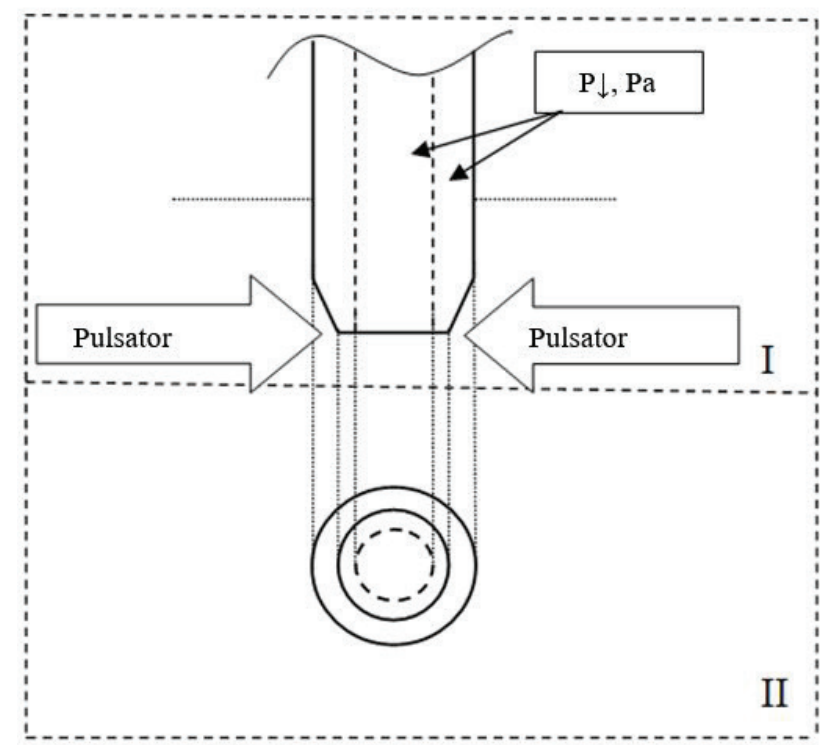

Fig. 1. Technical solution of dosing channel of plodder

The structural-mechanical properties of $\mathrm{Alg}_{2} \mathrm{Ca}$ gels, namely: module of momentary firmness $\left(\mathrm{E}_{\mathrm{fr}}, \mathrm{Pa}\right)$, module of elasticity $\left(\mathrm{E}_{\mathrm{el}}, \mathrm{Pa}\right)$, pliability $(\varepsilon, \mathrm{Pa})$, were determined using modified weights by Kargin-Sogolova by the study of deformation of compression of structured systems under chisel action at stable tension. Mathematical-statistical processing of the results of rheological studied was carried out using the program Microsoft Office Excel 2007.

The firmness of capsules on the model systems of encapsulated oils was studied under conditions of one-axial compression on modified weights by Kargin-Sogolova by the study of destructing effort (DE). DE was determined as a value of action of limiting tension on the sample that causes the 
crushing of the sample. For this aim the studied sample was placed on the platform, which position was regulated to the bringing of sample and chisel in the contact state, weights were unloaded and the limiting value of the load mass that leads to the crushing of sample was fixed. DE was determined by the formula:

$$
\mathrm{DE}=\frac{4 \cdot \mathrm{m} \cdot \mathrm{g}}{\pi \cdot \mathrm{d}^{2}}
$$

where DE - destructing effort, Pa; $\mathrm{m}$ - mass of load, $\mathrm{kg} ; \mathrm{g}$ - acceleration of free fall, $\mathrm{m} / \mathrm{s}^{2} ; \mathrm{d}-\mathrm{di}$ ameter of sample, $\mathrm{m}$.

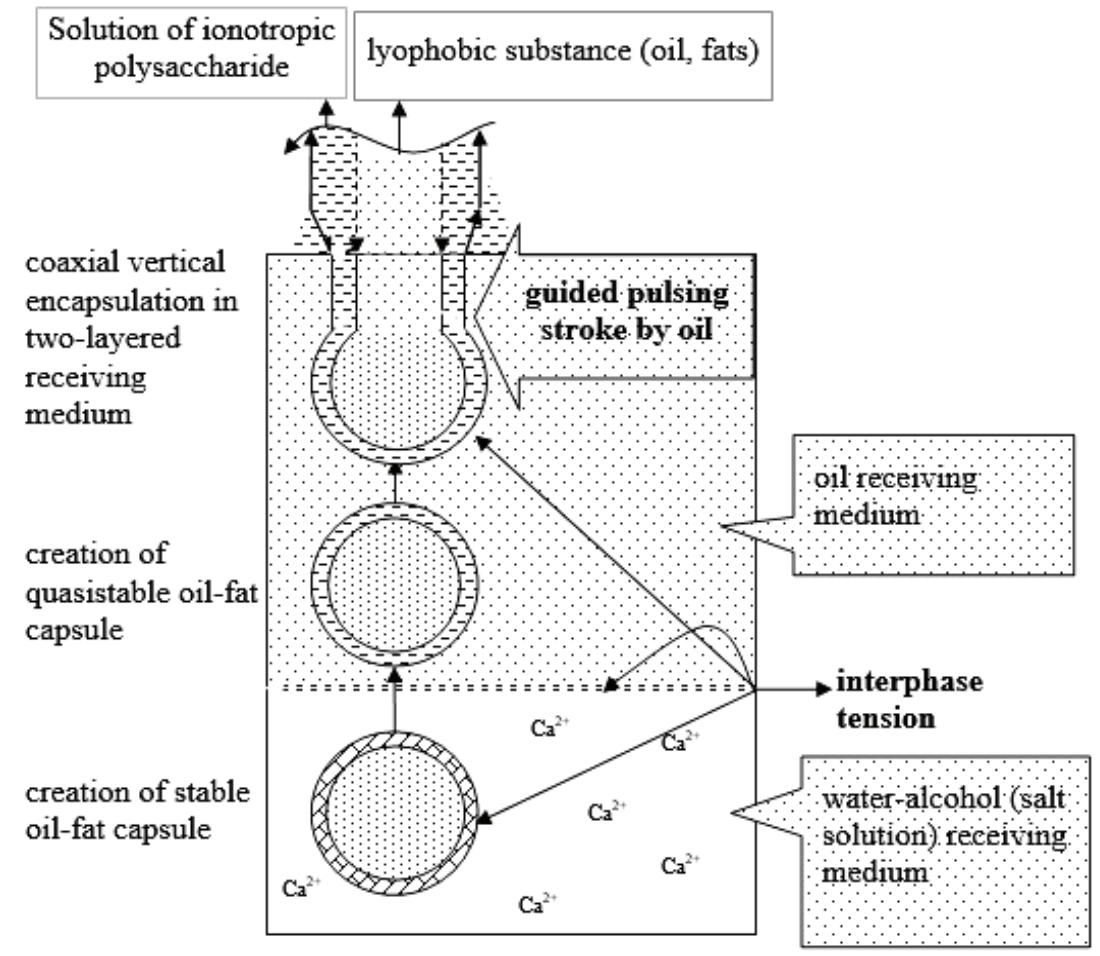

Fig. 2. Technical solution of the mechanism of encapsulated oils receiving

The quantity of dehydrated moisture from the capsule shells were determined by the weight method, namely - the mixture for encapsulation and formed capsules were weighted, and the increment of capsule mass was determined in percents by the ratio of determined masses to the capsule masses. The quantity of moisture, separated from capsules, was determined after their keeping during the given time.

Accumulation of dry substances in the $\mathrm{Ca}^{2+}$ water-alcohol solution was carried out under conditions of hydromodule 1:4, that is most convenient for experiment and for use of refractometric method of the study of dry substances [11].

The processing of experimental data, received within two-factor experiment was carried out in Microsoft Office Excel XP, of problem-oriented package of mathematical calculations Statistika. The reliability of received results was determined by calculation of Student coefficients $\left(\mathrm{t}_{\mathrm{ST}}\right)$ for accepted level of dependence $\mathrm{P}=0,05$ and correspondent $(\mathrm{n}-1)$ to the number of freedom degrees.

Experimental studies were carried out at scientific laboratories of Kharkov state university of food technology and trade (city Kharkov, Ukraine).

\section{Results}

Gravitation transfer of capsule to the zone of formation through the interphase layer "sunflower oil - $\mathrm{Ca}^{2}$ water-alcohol solution" is possible at the expense of increase of capsule mass as 
regulator of growth $\rho_{\mathrm{K}}$ that can be attained by introduction of third substances into the capsule composition, especially the white sugar. This way is prospective in the aspect of gravitation processes, because the density in interval of concentration $0,01 \%<\mathrm{C}_{\text {white sugar }}<40,0 \%$ increases in 1,23 times.

Under these conditions the properties of $\mathrm{Alg}_{2} \mathrm{Ca}$ gels will be conditioned by the properties of third substance in solution - white sugar (Fig. 3).

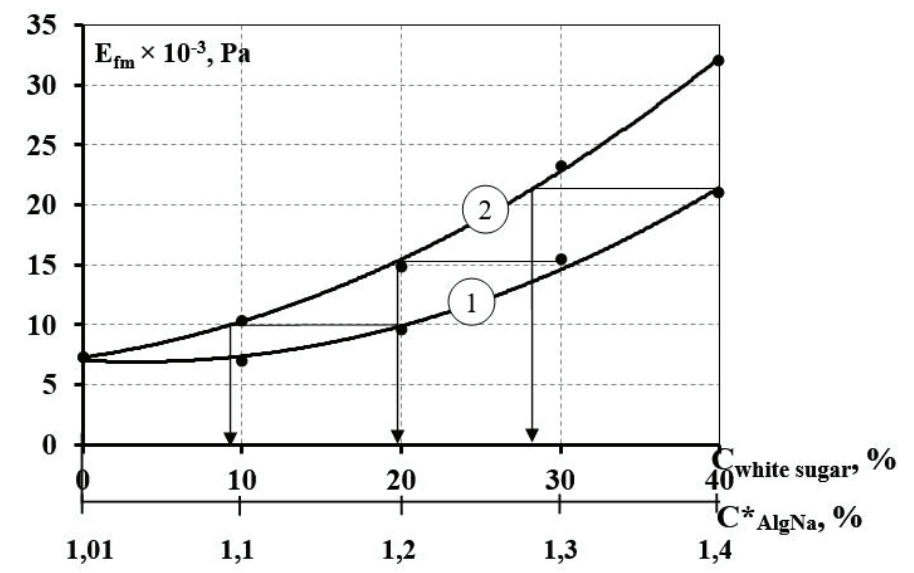

Fig. 3. Dependence of firmness module $\left(\mathrm{E}_{\mathrm{fr}}\right)$ of the model systems at $\mathrm{Ca}^{2+}$ ions concentration $0,048 \%$ and $\mathrm{AlgNa}$ concentration $1,0 \%$ in the system at the content of white sugar $10,0 \ldots 40,0 \%$ :

"water - $\mathrm{AlgNa}$ - white sugar" (1); "water - AlgNa" (2); C ${ }_{\mathrm{AlgNa}}-$ present value

The comparative matching of modules of momentary firmness of the module systems "water - AlgNa - white sugar" - curve 1, "water - AlgNa" - curve 2 (Fig. 3) confirmed the growth of firm properties with increase of AlgNa concentration relative to the water and formation of more hard gel (curve 1, Fig. 3) with increase of white sugar. At the same time the concentration of dry subjects, especially white sugar is important in recipe solution of $\mathrm{AlgNa}$. The model $\mathrm{Alg}_{2} \mathrm{Ca}$ gels with concentration $20,0 \ldots 40,0 \%$ correspond to diapason of the module of momentary firmness $\left(\mathrm{E}_{\mathrm{fr}}=10,0 \ldots 21,5\right) \times 10^{3} \mathrm{~Pa}$.

The comparison of dependencies of two constructed lines of trend 1, 2 allows state that the actual white sugar content $40,0 \%$ influences the properties of gel net and expresses the typical firm properties of gel in pure solvent with AlgNa concentration 1,41 $\pm 0,05 \%$. Taking into account the received data, we can state that with increase of $\mathrm{AlgNa}$ and white sugar concentrations the sodium alginate capsule shell creates the gel net with relatively lowered firmness indices and white sugar realizes plastifying function relative to $\mathrm{Alg}_{2} \mathrm{Ca}$ gel.

The dynamics of mass of $\mathrm{Alg}_{2} \mathrm{Ca}\left(\mathrm{C}_{\mathrm{AlgNa}}=1,0 \%\right)$ and $\left(\mathrm{C}_{\mathrm{AlgNa}}=1,5 \%\right)$ gel was studied (Fig. 4, 5) in stoichiometric value depending on ethanol concentration. On the graph we can see that the change of $\mathrm{Alg}_{2} \mathrm{Ca}$ gels mass takes place in multi-vector direction. It is connected with ethanol property to be a dehydrator of watered gels at increased concentration and to favor the salvation of gel-like system at the low ones. Obviously, such effect is connected with its ability to be an expressed donor of $\mathrm{H}^{+}$and acceptor of $\mathrm{OH}^{-}$remains between ethanol and water molecules at their interaction.

It is obvious from the regularities of changes of the samples mass (Fig. 4, 5) that water and water-alcohol solutions do not provide the stable size characteristics of the oil raw material encapsulation and cannot be used as a medium for their preservation without additional conditions.

The type of change of $\mathrm{Alg}_{2} \mathrm{Ca}$ gels mass (Fig. 6) at concentration $\mathrm{AlgNa} 1,0 \%$ and 1,5\%, kept during $\tau=6 \times 3600 \mathrm{~s}$ in sunflower oil at temperature $\mathrm{t}=20^{\circ} \mathrm{C}$, is characterized with low dynamics that is connected with the structure of $\mathrm{Alg}_{2} \mathrm{Ca}$ gels and their inability to release the free moisture in hydrophobic medium.

$\mathrm{Alg}_{2} \mathrm{Ca}$ gel does not essentially change its properties at technological-technical "way" of being in water-alcohol medium $\mathrm{Ca}^{2+}$. It was established, that the product does not change its properties at storage and realization with or without pouring, which role can be played by the wide assortment of hydrophobic substance. 


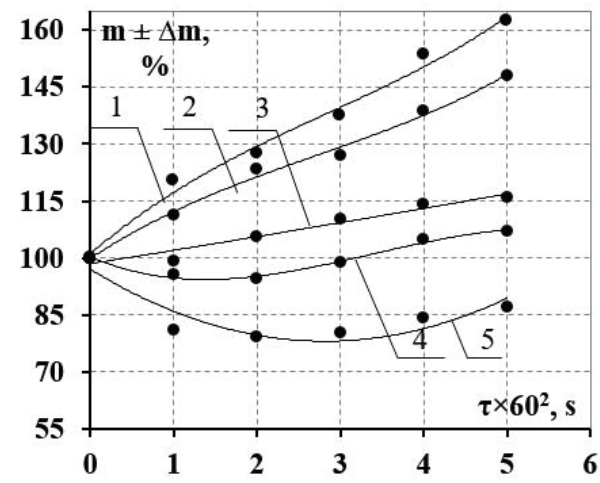

Fig. 4. The dynamic of mass $(\mathrm{m} \pm \Delta \mathrm{m}, \%)$ of $\mathrm{Alg}_{2} \mathrm{Ca}$ gel $\left(\mathrm{C}_{\mathrm{AlgNa}}=1,0 \%\right)$ in $\mathrm{Ca}^{2+}$ water-alcohol medium at ethanol concentration, alc. $\%: 1,2,3,4,5-10,0 ; 20,0 ; 30,0 ; 40,0 ; 50,0$ respectively

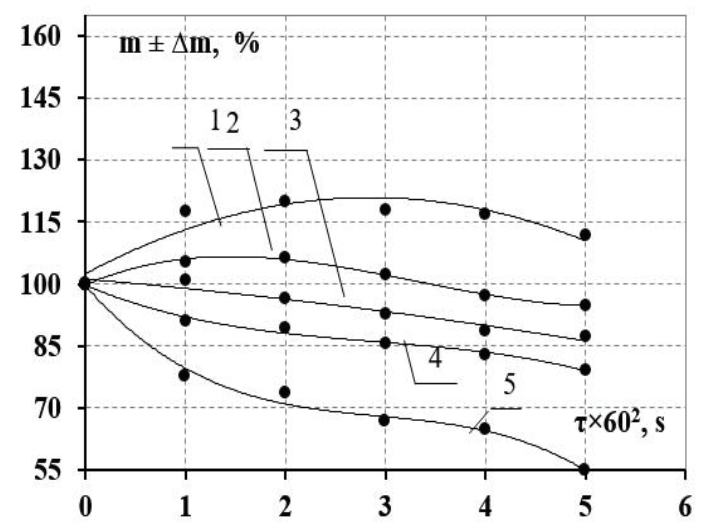

Fig. 5. The dynamic of mass $(\mathrm{m} \pm \Delta \mathrm{m}, \%)$ of $\mathrm{Alg}_{2} \mathrm{Ca}$ gel $\left(\mathrm{C}_{\mathrm{AlgNa}}=1,5 \%\right)$ in $\mathrm{Ca}^{2+}$, water-alcohol medium at ethanol concentration, alc. \%: 1, 2, 3, 4, $5-10,0 ; 20,0 ; 30,0 ; 40,0 ; 50,0$ respectively

\section{Conclusions}

The physical regulations of receiving of encapsulated oils were substantiated and parameters of gravitation transfer of quasistable capsule in water-alcohol solution $\mathrm{CaCl}_{2}$ of two-layered receiving medium on the author device under industrial conditions were determined. The capsule must be more by physical characteristic than the density of receiving medium that is expressed in ratio of capsule shell and internal component of sunflower oil $\left(\rho=926,0 \mathrm{~kg} / \mathrm{m}^{3}\right)$.

Analytic studies of the system "capsule-receiving medium" scientifically grounded the conditions of course of technology of oils encapsulation - general density of capsule, density of two-layered receiving medium, interphase crossing of phases limits of two-layered receiving medium. The composition of shells of encapsulated oils was grounded, it was established, that at concentration of white sugar $\mathrm{C}_{\text {white sugar }}=23,0 \%$ capsules are characterized with density $\left(\mathrm{E}_{\mathrm{fr}}=11,0 \times 10^{3} \mathrm{~Pa}\right)$ and stable organoleptic parameters of the product at storage.

The researches ground the principles and mechanism of receiving of encapsulated oils in industrial condition on the author equipment. The authors planned the series of experimental studies that allow study the behavior of shell of capsule, received at mixed gel-creation. The receiving of encapsulated product with new organoleptic parameters (taste, scent, firm properties of capsule shell) is planned to be used in technologies of leavened dough by the shortened term of production.

\section{References}

[1] Popkin, B. M. (2012). Global nutrition transition and the pandemic of obesity in developing countries. Nutrition reviews, 70 (1), 3-21. doi: 10.1111/j.1753-4887.2011.00456.x

[2] Kasprzak, M. M., Houdijk, J. G. M., Liddell, S., Davis, K., Olukosi, O. A., Kightley, S., Wiseman, J. (2016). Rapeseed napin and cruciferin are readily digested by poultry. Journal of Animal Physiology 
and Animal Nutrition. National Center for Biotechnology Information. Available at: https://www.ncbi.nlm. nih.gov/pubmed/27562881 doi: 10.1111/jpn.12576

[3] McHenry, B., Adee, E., Kimball, J., Prasad, P. V. V., Ciampitti, I. A. (2016). Balanced Nutrition and Crop Production Practices for Closing Sorghum Yield Gaps. New Prairie Press, 2 (5), 2. doi: 10.4148/23785977.1219

[4] Lim, J. Y., Kim, J. H., Min, S. H., Lee, M. H., Lee, M. J. (2016). Evaluation of Dietary Behavior among Elementary School Students in Seoul Area Using Nutrition Quotient for Children. Korean Journal of Food and Cookery Science, 32 (1), 84-95. doi: 10.9724/kfcs.2016.32.1.84

[5] Marcos, B., Bueno-Ferrer, C., Fernández, A. (2016). Innovations in Packaging of Fermented Food Products. Food Engineering Series, 311-333. doi: 10.1007/978-3-319-42457-6_15

[6] Chang, L. C., Kang, J. J., Gau, C. S. (2016). Development of the risk-based, phased-in approach for the international harmonization of the regulation of container closure systems for drugs in Taiwan. Regulatory Toxicology and Pharmacology, 77, 252-256. doi: 10.1016/j.yrtph.2016.03.018

[7] Jones, B. E., Knight, P. M., Walker, M. A.; assignee: Lilli Indastriz Limited. (1994). Sposob polucheniia tverdoi zhelatinovoi kapsuly. Patent RF № 4028207/14. MPK A61K9/48. Filed 10.09.1986. Available at: http://www.findpatent.ru/patent/201/2018305.html

[8] Gaserod, O., Klein, C., Larsen, Andersen, P. O.; assignee: Fmc Corporation. (2011). Seamless alginate capsules. Patent US 8357827 B2. Appl. № US 12/874,567. Filed 02.09.2010. Available at: https:// www.google.ch/patents/US20110059165

[9] Kailasapathy, K. (2015). Biopolymers for Administration and Gastrointestinal Delivery of Functional Food Ingredients and Probiotic Bacteria. Functional Polymers in Food Science, 2, 231-265. doi: $10.1002 / 9781119108580 . \operatorname{ch} 11$

[10] Horalchuk, A. B., Pyvovarov, P. P., Hrynchenko, O. O. et. al. (2006). Reolohichni metody doslidzhennia syrovyny ta kharchovykh produktiv ta avtomatyzatsiia rozrakhunkiv reolohichnykh kharakterystyk. Kharkiv: Kharkivskyi derzhavnyi universytet kharchuvannia ta torhivli, 63.

[11] DSTU ISO 2173:2007. Produkty z fruktiv ta ovochiv. Vyznachennia rozchynnykh sukhykh rechovyn refraktometrychnym metodom (ISO 2173:2003, IDT) (2010). Kyiv: Derzhspozhyvstandart Ukrainy, 11. 